\title{
The future is now: insights into finding tomorrow's pediatric radiologists
}

\author{
David Adam Bloom ${ }^{1}$ (D)
}

Received: 22 August 2019 /Revised: 11 October 2019 / Accepted: 12 November 2019 /Published online: 4 December 2019

(C) Springer-Verlag GmbH Germany, part of Springer Nature 2019

I decided several years ago that the last third of my career as a pediatric radiologist would be used to pursue my passion for medical education. I have always enjoyed teaching and wanted to make sure to give back to our specialty. Having been involved in medical student education for many years, even as early as the first week of M1 year at a newly created medical school, and doing as much as possible with regard to resident and fellow training, paying it forward was a constant personal motto. I remember having a conversation with Dr. Wilbur Smith, and he asked why I wanted to apply for the pediatric radiology coordinator position at our institution, a role requiring a great deal of paperwork and scheduling but with the bonus of really getting to know the rotating residents and having a significant footprint on their pediatric radiology experience. I simply said that helping as many residents find satisfaction in pediatric imaging as I had would allow all of us to know that we were leaving the specialty in good hands. I have never felt that more than today.

This brings us to a dilemma. Where are we headed as a specialty? Fewer residents are interested in pursuing a career in pediatric radiology, fellowship positions go unfilled, and the number of yearly graduates from accredited pediatric radiology fellowships is dwindling [1]. We all see this. It is disheartening to any educator, but more important, it is a loud and fierce warning bell for our specialty and radiology in general.

For those not familiar with the phrase " 2 minutes to midnight," it is a designation used by the Bulletin of the Atomic Scientists, an organization and publication of concerned scientists about the global threat related to potential annihilation

David Adam Bloom

radbloom@med.umich.edu

1 Section of Pediatric Radiology, C. S. Mott Children's Hospital, Department of Radiology, University of Michigan Health System, 1540 E. Hospital Drive, SPC 4252, Ann Arbor, MI 48109-4252, USA (nuclear and otherwise) [2]. A yearly review of the state of worldwide affairs informs the group on whether to move the minute hand closer to or farther from 12 o'clock midnight, signaling the degree of the threat to human survival. In 2018, with a multitude of potential threats around the world (North Korea, the unfolding of the Iran nuclear deal, devastation related to climate change), they moved the clock ahead to 2 minutes to midnight, the closest it has been since 1953, during the height of the Cold War [2]. I now look at our specialty and wonder whether we could be approaching 2 minutes to midnight.

The question is why. Why is pediatric radiology a less popular specialty than in years past? What are the reasons residents are choosing not to go into pediatric radiology, and are we addressing these issues in a meaningful way? Are we in a never-ending spiral, leading to more and more pediatric imaging being done by non-fellowship-trained radiologists?

I recently came across an Op-Med piece in Doximity titled "I Did the Math: Full-Time, Full-Service Doctors Cannot Ever Have a Work-Life Balance," by Steven F. Gordon, MD [3]. To summarize, it was an exercise in math to show that primary care physicians can never really achieve work-life balance, once you add on all of the non-generating relative value unit hours of electronic medical records, pre-authorizations, call coverage, etc. [3]. It got me wondering about work-life balance and its effect on radiology specialty choice. There has been much in the literature about this topic, as well as burnout and physician well-being. There have also been discussions regarding how to attract medical students to diagnostic radiology and how to similarly attract diagnostic radiology residents to pediatric radiology as a career $[4,5]$. Suggestions have been made to be in contact with students as early as possible, showing them the value added by pediatric radiologists, be engaging and enthusiastic around trainees, just to name a few. The problem is that we are doing this and yet the numbers are still trending downward. Show medical students how much patient contact pediatric radiologists can have. We have been doing that directly and indirectly for years, yet again the numbers are not rising. 
My mind was spinning with thoughts and ideas and then the lightbulb moment. Are we asking the right questions and are we looking in the right place for the pediatric radiologists of the future?

Let's start with the idea of pediatric radiologists having patient contact and that being a selling point for our specialty. It is true and has always been true, but what has happened is that the other diagnostic radiology specialties have started to catch up, so we do not stand out as much anymore. Interventional radiology, breast imaging, and abdominal proceduralists have all embraced the concept of getting to know your radiologist. It has been one of the strategic goals and a prior campaign of the American College of Radiology — "What is a radiologist?" and "Do you know your radiologist?" [6]. So, does direct patient contact truly distinguish us as a specialty?

What about work-life balance? I make it my business to ask rotating residents why they did not consider pediatric radiology as a career. There are varied individual answers but two come back more often than the rest. One is the perception that pediatric radiologists work harder than our colleagues in adult radiology. Perhaps that is in part the result of being perpetually short-staffed, the vicious cycle we are trying to avoid. The second is call coverage. They know how often we are on call and how many times a night we get paged, for they see the schedule and are the ones paging us at all hours. And they see their adult radiologist counterparts who are primarily covered off-hours by an emergency radiology division that essentially obviates the need for pager coverage by the day staff; or, in the case of private practice, they are covered by nighthawk services. Many of the emergency radiology staff are subspecialtytrained in neuroradiology and abdominal imaging. Yes, the adult divisions do take call, but it is typically a select few and related to sub-subspecialty work, especially interventional procedures. Almost all diagnostic work is done by the emergency radiologists at our institution. I have yet to work with or meet an emergency radiologist who was trained in pediatric radiology and who did not work at one of our largest children's hospitals and in a nighttime/pediatric radiology emergency division. Intussusception - in you go. Neonatal bowel obstruction - in you go. Work by day, pager by night, week at a time. The residents see this. What choice would you make, keeping in mind work-life balance and what this means to the millennial generation? Are we competing against the adult specialties that allow defined times for work and for life?

Now would be the time you say, "But if they love taking care of children, none of that will matter," or "No job is perfect, but if you do what you love, you will never work a day in your life." Let's examine that. Think about why you or someone you know went into pediatric radiology. Did you consider other options? In medical school, was family medicine, pediatrics, or obstetrics/gynecology an option for you (the rotations routinely involved in taking care of children)? Have you always had a fondness for the care of children? Now let's look at the current pool of diagnostic radiology residents. First, the number of residents available to recruit into our specialty has decreased with the creation of a separate interventional radiology-diagnostic radiology (IR-DR) pathway, and the attendant decreases in the number of diagnostic residency (DR) slots. With a smaller denominator, how many of those residents went into radiology with a specialty related to pediatric care as their second choice and would be inclined to consider a future in pediatric radiology? How many wanted to make sure they maintained contact with pediatric patients while in radiology? Did most of their experiences as medical students involve adult radiology, and is that what enticed them to pursue diagnostic radiology in the first place? Who would want to be a pediatric radiologist? If you consider pediatric radiology as a pediatric subspecialty as much as a radiology subspecialty, then our pool of potential candidates would be the medical students who are strongly thinking about some type of pediatric career, with the subspecialty choice still up in the air. As a reminder, Dr. John Caffey was a pediatrician, as were many of the other giants in our field before they pursued a career in pediatric radiology.

Let us also consider the number of women going into diagnostic radiology and how it may impact the pediatric radiology workforce's future. Current literature points to the fact that in 2017 , for the first time, women outnumbered men entering medical school, and yet only $27 \%$ of diagnostic residents are women, ranking it the 11th most common career choice for female medical students [7]. Yet women make up $47 \%$ of all academic pediatric radiologists [8]. Considering the relatively small percentage of women entering diagnostic radiology residencies but the popularity of pediatric radiology as a subspecialty choice for women, are we limiting our ability to grow our specialty by not finding a solution to the gender gap at the diagnostic radiology residency level?

If you use the interventional radiology model as a comparison, the Society of Interventional Radiology (SIR) decided to work with students early in medical school, eventually coming up with their own independent residency. But who was their audience? It was not just students who were born to be interventional radiologists. It was any student who was interested in procedural/surgical type work. The SIR simply showed them another pathway to a career using their hands. So who should we look to?

To confound matters, I am not sure that any medical student who is passionate about pediatric health care would want to put his or her life on hold for 4 years to study diagnostic radiology and sit for core and certifying exams if all they want to do is take care of children.

The point is, we are barely scratching the surface on why we could be on our way to 2 minutes to midnight [2]. To attract medical students into diagnostic radiology and pediatric radiology in particular, we have to find the students who 
are either (1) passionate about pediatrics (and again, how do we convince them to first do diagnostic radiology and put their love of pediatric care on hold for most of the next 5 years?) or (2) passionate about radiology and pediatrics, as if those were their two match lists (I cannot imagine that is a large number). To attract from the diagnostic radiology cohort, we have to (1) find the ones passionate about pediatric health care or persuade them that it is a worthwhile pathway, (2) dispel the myths that seem to perpetuate in relation to being a pediatric radiologist (e.g., less pay, less interesting work such as less $\mathrm{CT}$ and MRI), (3) dispel the myth that they must work only at a children's hospital and work in academia, (4) make them realize that being a specialist and generalist at the same time is a great thing (I often hear from the residents that it seems like there is too much to learn - not sure where that came from compared to the other specialties in radiology) and (5) level the playing field compared to the adult radiology specialties (less or no call, improved salaries, etc. - make our careers mirror how adult radiology is currently practiced).

What can we do? We should clearly keep doing what we can to interact with medical students early in their careers and show them the value we bring to teaching, patient care, and research. But it is also time to think outside the proverbial box. We want to find students passionate about pediatric care and who enjoy working with technology. We perhaps need to create a reasonable pathway for them like interventional radiology did. Can we create a pathway that does not take them away from their passion for so many years and yet gives them the requisite skills to be a competent general diagnostic radiologist as well as pediatric imaging specialist? We have to realize that we are perhaps already targeting a group (diagnostic radiology residents) with a preset idea for their future, and taking care of children was not a priority for them at the time of their specialty choice. The number of pediatric radiology fellows we gain from the diagnostic radiology residency pool will not dramatically increase with our current strategies alone, yet the need for pediatric radiologists has never been greater. We need to assume that we are essentially maximizing that numerator already, save for a few here or there. We do need to keep pace with our adult colleagues with regard to pay, work-life balance, call, and the like. We need to carefully examine the reasons for a persistent gender gap in diagnostic radiology and tackle the issue head-on because pediatric radiology has always been and continues to be a popular subspecialty choice among women radiology residents. But most of all, we need to stand on the shoulders of the giants we admire. Look down - it seems to look as much like a group of pediatricians as a group of radiologists. I believe we may in part be looking in the wrong place.

\section{Compliance with ethical standards}

Conflicts of interest None

\section{References}

1. Farmakis SG, Hardy AK, Thomas KB et al (2019) Changes in factors influencing fellowship choices among radiology residents from 2008 to 2018 and methods that may increase interest in the pediatric radiology subspecialty. Pediatr Radiol 49:1132-1141

2. Bulletin of the Atomic Scientists (2019) The new abnormal: it is still 2 minutes to midnight. https://thebulletin.org/doomsday-clock. Accessed 7 Nov 2019

3. Gordon SF (2019) I did the math: full-time, full-service doctors cannot ever have a work-life balance. Doximity. https://opmed. doximity.com/articles/i-did-the-math-full-time-full-service-doctorscannot-ever-have-a-work-life-balance. Accessed 7 Nov 2019

4. Taylor CS, Weatherly B, Farley EP et al (2018) Generating medical student interest in the field of radiology. J Am Coll Radiol 15:340 342

5. Pfeifer CM (2018) Declining interest in pediatric radiology prompts a call to action. J Am Coll Radiol 15:490-492

6. American College of Radiology (2019) What is a radiologist? https:// www.acr.org/Practice-Management-Quality-Informatics/PracticeToolkit/Patient-Resources/About-Radiology. Accessed 7 Nov 2019

7. Gaetke-Udager K, Magid D, Smith M et al (2019) Recruiting future radiologists: how can we do better? Acad Radiol. https://doi.org/10. 1016/j.acra.2019.08.001

8. Counter WB, Khurshid K, Jalal S et al (2019) Gender differences among academic pediatric radiology faculty in the United States and Canada. Acad Radiol. https://doi.org/10.1016/j.acra.2019.06.011

Publisher's note Springer Nature remains neutral with regard to jurisdictional claims in published maps and institutional affiliations. 